\title{
Thrice-weekly temocillin administered after each dialysis session is appropriate for the treatment of serious Gram-negative infections in haemodialysis patients
}

\author{
Stefaan J. Vandecasteele ${ }^{\mathrm{a}, 1}$, Ana C. Miranda Bastos ${ }^{\mathrm{b}, \mathrm{c}, \mathrm{d}, 1}$, Arnaud Capron $^{\mathrm{e}, \mathrm{f}}$, \\ Anne Spinewine $^{\mathrm{d}}$, Paul M. Tulkens ${ }^{\mathrm{b}, \mathrm{c}}$, Françoise Van Bambeke ${ }^{\mathrm{b}, \mathrm{c}, *}$ \\ a Nephrology and Infectious Diseases Department, AZ Sint-Jan Brugge-Oostende AV, AV Ruddershove 10, 8000 Brugge, Belgium \\ b Pharmacologie cellulaire et moléculaire (LDRI/FACM), Av. E. Mounier 73, bte B1.73.05, B-1200 Brussels, Belgium \\ ${ }^{c}$ Center for Clinical Pharmacy, Université catholique de Louvain, Av. E. Mounier 73, bte B1.73.05, B-1200 Brussels, Belgium \\ d Clinical Pharmacy Research Group (LDRI/CLIP), Av. E Mounier 72, bte 01.72.02, B-1200 Brussels, Belgium \\ e Clinical Chemistry Department, Cliniques Universitaires St Luc, Av. Hippocrate 10, B-1200 Brussels, Belgium \\ ${ }^{\mathrm{f}}$ Louvain Center for Toxicology and Applied Pharmacology, Université catholique de Louvain, Av. E. Mounier 53, Box B1-52-12, B-1200 Brussels, Belgium
}

\section{A R T I C L E I N F O}

\section{Article history:}

Received 17 July 2015

Accepted 8 September 2015

\section{Keywords:}

ESRD

Gram-negative infection

Intermittent haemodialysis

Pharmacodynamics

Pharmacokinetics

Temocillin

\begin{abstract}
A B S T R A C T
In patients with end-stage renal disease (ESRD) treated with intermittent haemodialysis, a limited number of antibiotics have been studied for their suitability for parenteral administration after dialysis sessions only in a thrice-weekly regimen. Temocillin is a $\beta$-lactam antibiotic with a long half-live and enhanced activity against most Gram-negative bacteria, including extended-spectrum $\beta$-lactamaseproducers, thus making it an ideal candidate for use in this setting. This study aimed to evaluate the reliability of thrice-weekly parenteral temocillin in haemodialysis patients by characterising the pharmacokinetics of total and free temocillin. Free and total temocillin concentrations were determined with a validated HPLC method in 448 samples derived from 48 administration cycles in 16 patients with ESRD treated with intermittent haemodialysis and temocillin. Pharmacokinetics were non-linear partly due to saturation in protein binding. Median clearance and half-life for the free drug during intradialysis and interdialysis periods were $113 \mathrm{~mL} / \mathrm{min}$ vs. $26 \mathrm{~mL} / \mathrm{min}$ and $3.6 \mathrm{~h}$ vs. $24 \mathrm{~h}$, respectively, with dialysis extracting approximately one-half of the residual concentration. The free temocillin concentration remained $>16 \mathrm{mg} / \mathrm{L}$ ( $\mathrm{MIC}_{90}$ threshold for most Enterobacteriaceae) during $48 \%, 67 \%$ and $71 \%$ of the dosing interval for patients receiving $1 \mathrm{~g}$ q24h, $2 \mathrm{~g}$ q $48 \mathrm{~h}$ and $3 \mathrm{~g} \mathrm{q} 72 \mathrm{~h}$, respectively, suggesting appropriate exposure for the two latter therapeutic schemes. Temocillin administered on dialysis days only in a dosing schedule of $2 \mathrm{~g} \mathrm{q} 48 \mathrm{~h}$ and $3 \mathrm{~g} \mathrm{q} 72 \mathrm{~h}$ is appropriate for the treatment of serious and/or resistant Gram-negative infections in patients with ESRD undergoing intermittent haemodialysis. These doses are higher than those previously recommended.
\end{abstract}

(c) 2015 Elsevier B.V. and the International Society of Chemotherapy. All rights reserved.

\section{Introduction}

Patients with end-stage renal disease (ESRD) suffer significantly higher mortality than the general population, with values 48 times higher in the 20- to 44-year-old age group and 7 times higher in the over 75 years age group [1]. Infections, especially

\footnotetext{
* Corresponding author. Present address: Pharmacologie cellulaire et moléculaire, Université catholique de Louvain, Avenue E. Mounier 73, B1.73.05, B-1200 Brussels, Belgium. Tel.: +32 27647378 .

E-mail address: francoise.vanbambeke@uclouvain.be (F. Van Bambeke).

1 These authors contributed equally to this work.
}

septicaemia and pulmonary infections, are the second leading cause of death in this population [2]. Historically, Gram-positive infections were predominant in the haemodialysis population [3]. However, in the past few years a concerning rise in infections caused by Gram-negative pathogens with increasing rates of drug resistance in dialysis patients has fuelled a renewed interest in this field [3-5]. Parenteral antibiotics that permit thrice-weekly dosing after each dialysis session are preferable because they can reduce hospitalisation duration and costs as well as enhance quality of life [1]. Whilst this common practice is supported by strong clinical data for the treatment of Gram-positive infections with cefazolin [6] or vancomycin [7], the antibiotics most frequently administered on dialysis days only for the treatment of Gram-negative infections 


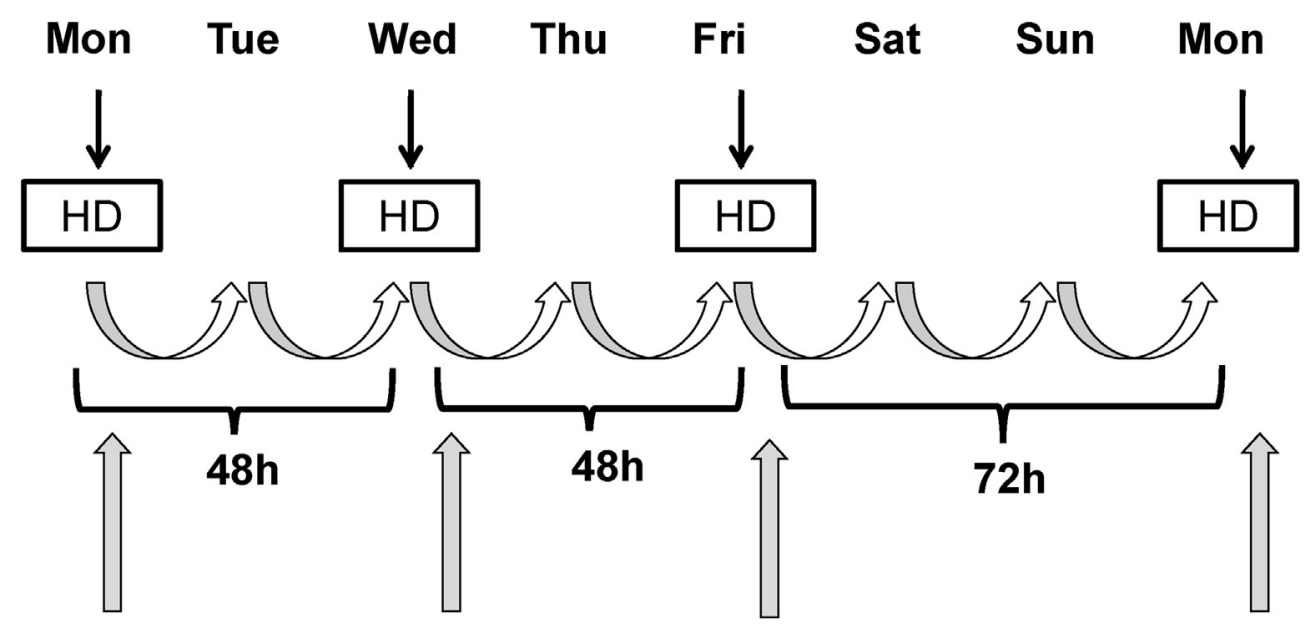

\section{$2 \mathrm{~g}$ Temocillin
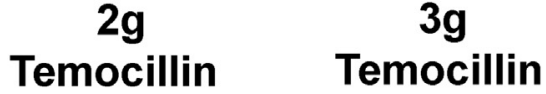 \\ Temocillin}

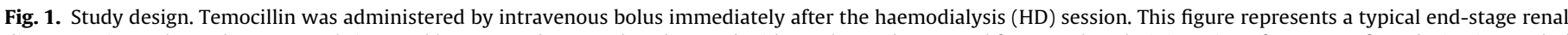

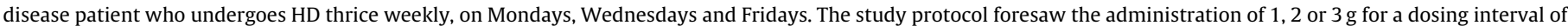
$24 \mathrm{~h}, 48 \mathrm{~h}$ or $72 \mathrm{~h}$, respectively. The 24 -h interdialytic period is not represented in this figure.

have been shown to lead to inadequate exposure (ceftazidime) [8] or unacceptable toxicity (aminoglycosides) [9].

In this setting, temocillin (an intravenous $\beta$-lactam antibiotic with a long half-life [10]) constitutes a valuable candidate as an anti-Gram-negative agent in settings where Pseudomonas aeruginosa can be excluded [11]. Moreover, the remarkable stability of temocillin against most $\beta$-lactamases, including AmpC, extended-spectrum $\beta$-lactamases and most carbapenemases, fuelled a recent interest in this antibiotic as a carbapenem-sparing agent [12]. For time-dependent antibiotics such as $\beta$-lactams, the probability of therapeutic success is related to the proportion of the dosing interval during which their free concentration exceeds the minimum inhibitory concentration (MIC) of the offending organism [13]. Therefore, their elimination rate will be a critical determinant in their overall efficacy and will dictate the frequency of their administration.

Little is known, however, about temocillin pharmacokinetics/pharmacodynamics in ESRD patients as well as its dialysability with contemporary high-flux haemodialysers [11,14]. Its primarily renal elimination (mainly by glomerular filtration in unchanged form) and long serum half-life compared with other $\beta$-lactams [10] render it suitable to be administered on haemodialysis days only. This study aimed: (i) to characterise the pharmacokinetics and dialytic clearance of temocillin in patients undergoing intermittent haemodialysis; (ii) to determine the fraction of the dosage interval during which the free concentration exceeds the MIC of target organisms if administered after each haemodialysis session; and (iii) to propose and validate a dosing schedule on dialysis days only.

\section{Methods}

\subsection{Study design and population}

This prospective, single-centre (tertiary-care renal unit in Belgium), open-label, non-randomised clinical study characterised the pharmacokinetics of temocillin administered on dialysis days only using a 1-, 2- or 3-day dosing interval. Patients undergoing intermittent haemodialysis for ESRD for whom treatment with temocillin was indicated according to the attending physician were eligible for the study. Exclusion criteria were: (i) age <18 years; (ii) estimated life expectancy of $<24 \mathrm{~h}$ due to major co-morbid conditions; (iii) pregnancy; (iv) IgE-mediated allergy to penicillins; or (v) patients not giving informed consent. The attending physician determined the indication for temocillin use as well as its duration. The dialysis schedule was according to clinical state of the art of the study site and was not altered for the purpose of the study. Urea clearance $(K t / V)$ was $>1.2$; blood flow rates were set as high as possible with a maximum of $400 \mathrm{~mL} / \mathrm{min}$ and pre-pump pressures not lower than $-250 \mathrm{mmHg}$, unless there was a confirmed disequilibrium syndrome. Blood flow rate, dialysate flow rate, time and other components of the dialysis prescription were determined according to the clinical need by the attending physician. The dialysers used were FX80 and FX10 (Fresenius Medical Care AG \& Co., Bad Homburg, Germany).

\subsection{Temocillin}

Temocillin (Eumedica SA, Brussels, Belgium) was used throughout the study period. Temocillin (1-3 g) was dissolved in $25-75 \mathrm{~mL}$ of water for injection and was administered intravenously over a 5min period directly after dialysis. In analogy with what is done with cefazolin [15], a fixed temocillin dosing schedule of $1 \mathrm{~g}$ for a $24-\mathrm{h}$ (1-day) dosing interval, of $2 \mathrm{~g}$ for a 48 -h (2-day) dosing interval and of $3 \mathrm{~g}$ for a 72-h (3-day) dosing interval was used (Fig. 1).

\subsection{Sample collection}

Blood samples were drawn: (i) just before and at 0.5, 3, 6, 12 , 20 (before dialysis) and $24 \mathrm{~h}$ (at the end of dialysis) after temocillin administration when patients were dialysed with a 1-day interval; (ii) just before and at $0.5,3,6,12,24,36,44$ (before dialysis) and $48 \mathrm{~h}$ (at the end of dialysis) after temocillin administration when patients were dialysed with a 2-day interval; or (iii) just before and at $0.5,3,6,12,24,36,48,68$ (before dialysis) and $72 \mathrm{~h}$ (at the end of dialysis) after temocillin administration when patients were dialysed with a 3-day interval. Additional blood samples were taken 1 , 2,3 and $4 \mathrm{~h}$ after the start of dialysis. All samples were taken from an arterial or venous catheter. Serum samples obtained by centrifugation after blood clotting were frozen at $-80^{\circ} \mathrm{C}$ immediately after sampling. 


\subsection{Temocillin assays}

Temocillin total serum concentrations were assayed by highperformance liquid chromatography (HPLC) with ultraviolet detection [16]. Free concentrations were determined by HPLC tandem mass spectrometry after ultrafiltration of serum samples $\left(2000 \times \mathrm{g}, 25^{\circ} \mathrm{C}, 20 \mathrm{~min}\right)$ with an Amicon ${ }^{\circledR}$ Ultra-15 device (NMWL $30 \mathrm{~K}$; Merck-Millipore, Merck KGaA, Darmstadt, Germany) as validated previously [17]. In brief, reverse-phase chromatography was performed using as mobile phase a gradient varying linearly from $100 \% 0.1 \%$ formic acid in water to $100 \% 0.1 \%$ formic acid in acetonitrile with a $0.3 \mathrm{~mL} / \mathrm{min}$ flow rate. Molecular ions were detected in positive electrospray ionisation mode. In addition, the following parameters were also recorded in all patients: time of drug administration; duration of dialysis and of the interdialytic interval; dry body weight (determined at the end of dialysis); mean blood flow; filter used; total volume dialysed; total ultrafiltration; urea and creatinine concentration; patient age; and dialysis vintage (length of time on dialysis).

\subsection{Data analysis}

Key pharmacokinetic (PK) parameters during the interdialytic period [volume of distribution $\left(V_{\mathrm{d}}\right)$, clearance $(\mathrm{CL})$, area under the concentration-time curve (AUC) and elimination half-life $\left(t_{1 / 2}\right)$ ] were estimated using the non-compartmental 'PK' package (PK version 1.3-2, CRAN) for R 3.0.2 using RStudio 0.98.501 (RStudio, Boston, MA). During the dialysis period, the following parameters were estimated:

$\mathrm{Fe}=\left(C_{\mathrm{s}, \text { pre }}-C_{\mathrm{s}, \text { post }}\right) / C_{\mathrm{s} \text {,pre }}$

where Fe is the fraction eliminated by dialysis and $C_{\mathrm{s} \text {,pre }}$ and $C_{\mathrm{s} \text {,post }}$ are serum concentrations of temocillin at the beginning and end of haemodialysis, respectively [18];

$\mathrm{CL}_{\mathrm{HD}}=\left[\left(C_{\mathrm{s}, \text { pre }}-C_{\mathrm{s}, \text { post }}\right) \cdot V_{\mathrm{d}} / \mathrm{AUC}_{\mathrm{HD}}\right]-\mathrm{CL}$

where $C L_{H D}$ and $A U C_{H D}$ are the haemodialysis clearance and the area under the concentration-time curve during haemodialysis calculated by the trapezoidal rule, respectively [19];

$t_{1 / 2 \mathrm{HD}}=\ln (2) V_{\mathrm{d}} /\left(\mathrm{CL}-\mathrm{CL}_{\mathrm{HD}}\right)$

where $t_{1 / 2 \mathrm{HD}}$ is the elimination half-life during haemodialysis [20]; and

$\mathrm{URR}=\left(\mathrm{BUN}_{\text {pre }}-\mathrm{BUN}_{\text {post }}\right) / \mathrm{BUN}_{\text {pre }}$

where URR is the urea reduction ratio and $\mathrm{BUN}_{\text {pre }}$ and $B U N_{\text {post }}$ are the pre- and post-dialysis blood urea nitrogen (mg/dL) [19]. Data were pooled by dose and were analysed independently, irrespective of sequence of doses.

The time during which free concentration $(f T)$ stayed above a given MIC was calculated by linear interpolation between measured values for the different dosing regimens. Target attainment rate was calculated considering the $f \mathrm{~T}$ ensuring a coverage of MIC up to $8 \mathrm{mg} / \mathrm{L}$ (temocillin breakpoint for systemic infections from the British Society of Antimicrobial Chemotherapy (BSAC) [21]) and $16 \mathrm{mg} / \mathrm{L}$ (presumed MIC for $>90 \%$ of Enterobacteriaceae [22]).

\subsection{Statistical analyses}

Multiple comparisons were analysed by analysis of variance (ANOVA). Overall, a $P$-value of $\leq 0.05$ was considered statistically significant. Since two tests were carried out independently, Bonferroni-corrected significance thresholds of $P \leq 0.025$ were used to compensate for the increased type 1 error. Analyses were conducted using R 3.0.2 with RStudio 0.98.501.
Table 1

Patient characteristics $(n=16)$.

\begin{tabular}{lcc}
\hline Characteristic & Median & Range \\
\hline Age (years) & 68.5 & $24-91$ \\
Follow-up (days) & 5.5 & $2-9$ \\
Dosing cycles/subject & 3 & $1-6$ \\
Dry body weight (kg) & 73.1 & $41.5-104$ \\
Dialysis characteristics & & \\
$\quad$ Vintage (days) & 453 & $4-2475$ \\
$Q_{\text {Blood }}(\mathrm{mL} / \mathrm{min})$ & 328 & $154-396$ \\
$Q_{\text {Dialysate }}(\mathrm{mL} / \mathrm{min})$ & 500 & $500-500$ \\
Ultrafiltration (mL) & 1800 & $599-3200$ \\
$\quad$ Kt/V & 1.51 & $0.87-1.88$ \\
Laboratory parameters & 3.3 & $2.1-4.4$ \\
$\quad$ Albumin (g/dL) & 19 & $12-40$ \\
AST (U/L) & 107 & $10-169$ \\
BUN & 6.5 & $1.26-10.29$ \\
Creatinine & Pre-dial $(\mathrm{mg} / \mathrm{dL})$ &
\end{tabular}

$Q_{\text {Blood }}$, blood flow rate; $Q_{\text {Dialysate }}$, dialysate flow rate; $K t / V$, urea clearance; $A S T$, aspartate aminotransferase; BUN, blood urea nitrogen; pre-dial, pre-dialysis.

\section{Results}

\subsection{Patients and treatment}

Sixteen patients were included in the study, including 14 males and 2 females. Their underlying kidney diseases were diabetes $(n=5)$ and/or nephroangiosclerosis $(n=7)$, chronic glomerulonephritis $(n=2)$, interstitial nephritis $(n=1)$, polycystic kidney disease $(n=1)$, congenital reflux or hypoplasia $(n=2)$ and acute tubular necrosis $(n=2)$. All patients were given temocillin as part of regular medical therapy for suspected or documented Gramnegative infection. Sepsis was observed in $44 \%$ of patients, and infection diagnosis included vascular necrosis, pyelonephritis, peritonitis, urinary tract infection, abscess, osteomyelitis, prostatitis, pneumonia, endocarditis and cystitis. The causative pathogen identified in 11 (69\%) of the patients was a Gram-negative organism from the Enterobacteriaceae family: Escherichia coli $(36 \% ; n=4)$; Klebsiella oxytoca ( $27 \% ; n=3)$; Klebsiella cloacae $(27 \% ; n=3)$; and Klebsiella pneumoniae $(9 \% ; n=1)$. Further patient characteristics are summarised in Table 1 . A total of 48 concentration-time curves (from the administration of temocillin until the end of the following dialysis session) were included in this analysis, including 4 for $1 \mathrm{~g}$ every $24 \mathrm{~h}$ (q24h), 31 for $2 \mathrm{~g}$ every $48 \mathrm{~h}$ (q48h) and 13 for $3 \mathrm{~g}$ every $72 \mathrm{~h}(\mathrm{q} 72 \mathrm{~h}$ ) (the length of the interdialytic interval was determined by the patient's clinical condition). All patients were haemodialysed over $4 \mathrm{~h}$.

\subsection{Pharmacokinetics}

The mean serum concentration-time profiles of temocillin are shown in Fig. 2. Both the actual total and free temocillin concentrations were measured because (i) only the free concentration is anticipated to be pharmacologically active and (ii) there are huge variations in protein binding in patients with advanced renal failure [23], which makes reference to standard populations for extrapolating free concentrations from measured total concentrations inadequate. Data analysis was carried out independently for the interdialytic and intradialytic period. Key PK parameters during the interdialytic period are summarised in Table 2 both for the total and free temocillin concentrations.

Exposure to total or free temocillin, determined by the area under the concentration-curve up to the last measurable concentration (excluding dialysis) $\left(\right.$ AUC $_{\text {last }}$ ), was not proportional to the dose $(P \leq 0.025)$, suggesting non-linear pharmacokinetics. Comparison of PK parameters for total and free drug showed that the $\mathrm{AUC}_{\text {last }}$ for the free concentration was 3-fold lower than for the 

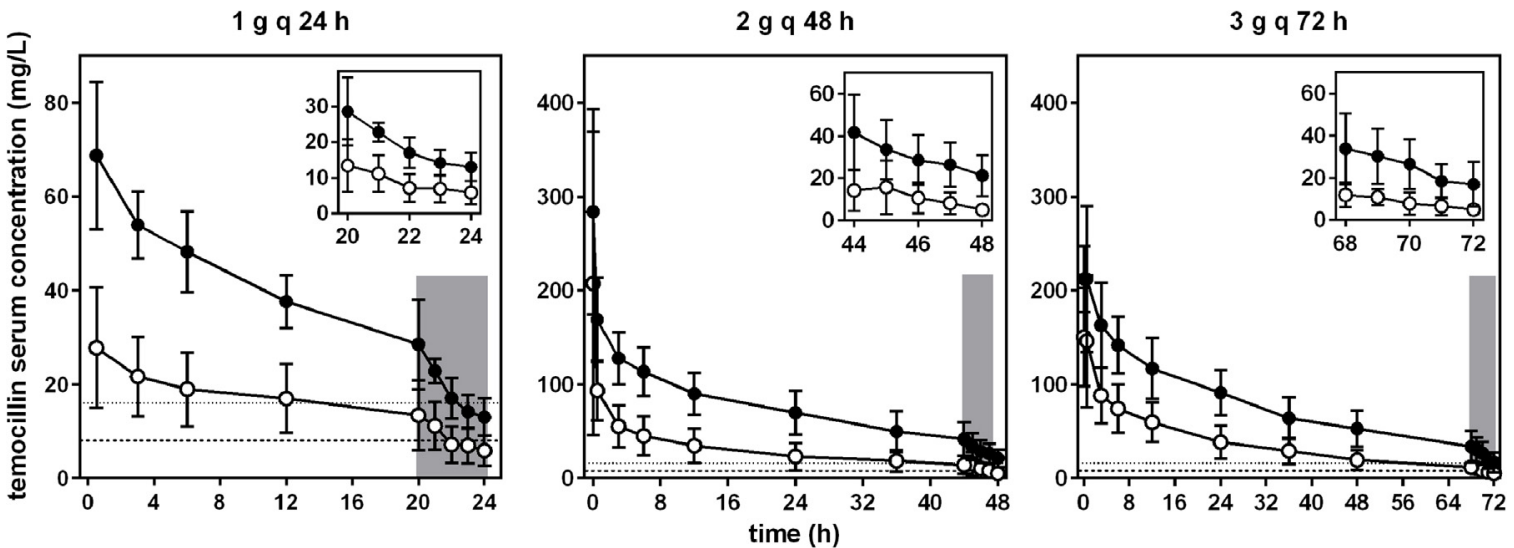

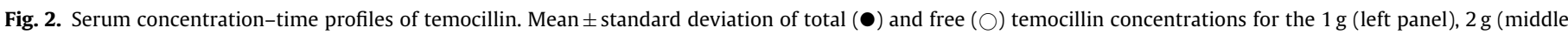
panel) and $3 \mathrm{~g}$ (right panel) dosing regimens. Greyed areas correspond to the haemodialysis period ( $4 \mathrm{~h}$ ), with data shown in details in the inset.

Table 2

Pharmacokinetic (PK) parameters ${ }^{\mathrm{a}}$ for total and free temocillin concentrations for the three dosing regimens during the interdialytic period.

\begin{tabular}{|c|c|c|c|c|c|c|}
\hline \multirow[t]{2}{*}{ PK parameter } & \multicolumn{3}{|c|}{ Total concentrations } & \multicolumn{3}{|c|}{ Free concentrations } \\
\hline & $1 \mathrm{~g} \mathrm{q} 24 \mathrm{~h}$ & $2 \mathrm{~g} \mathrm{q} 48 \mathrm{~h}$ & $3 \mathrm{~g} \mathrm{q} 72 \mathrm{~h}$ & $1 \mathrm{~g} \mathrm{q} 24 \mathrm{~h}$ & $2 \mathrm{~g} \mathrm{q} 48 \mathrm{~h}$ & $3 \mathrm{~g} \mathrm{q} 72 \mathrm{~h}$ \\
\hline $\mathrm{AUC}_{\text {last }}(\mathrm{mg} \mathrm{h} / \mathrm{L})$ & $781(83)$ & $3352(895)$ & $5484(1661)$ & $276(127)$ & $1257(651)$ & $2677(858)$ \\
\hline $\mathrm{AUC}_{\mathrm{inf}}(\mathrm{mg} \mathrm{h} / \mathrm{L})$ & $1749(813)$ & $5088(1978)$ & $7621(2925)$ & $713(620)$ & $1805(988)$ & $3122(1024)$ \\
\hline$V_{\mathrm{d}}(\mathrm{L})$ & $17.7(4.2)$ & $15.6(5.5)$ & $20.7(5.4)$ & $60.6(28.1)$ & $43.9(19.4)$ & $33.3(10.3)$ \\
\hline$V_{\mathrm{d}} / W_{\mathrm{t}}(\mathrm{L} / \mathrm{kg})$ & $0.26(0.09)$ & $0.23(0.10)$ & $0.31(0.10)$ & $0.8(0.2)$ & $0.6(0.2)$ & $0.5(0.1)$ \\
\hline $\mathrm{CL}(\mathrm{mL} / \mathrm{min})$ & $11.2(5.1)$ & $7.6(2.9)$ & $7.5(3.1)$ & $43(39)$ & $26(16)$ & $18(6)$ \\
\hline $\mathrm{CL} / W_{\mathrm{t}}(\mathrm{mL} / \mathrm{min} / \mathrm{kg})$ & $0.16(0.07)$ & $0.11(0.06)$ & $0.12(0.06)$ & $0.6(0.4)$ & $0.4(0.2)$ & $0.3(0.1)$ \\
\hline$t_{1 / 2}(\mathrm{~h})$ & $22.5(14.0)$ & $26.0(8.9)$ & $35.8(16.9)$ & $23.6(14.8)$ & $24.1(13.4)$ & $22.8(6.0)$ \\
\hline
\end{tabular}

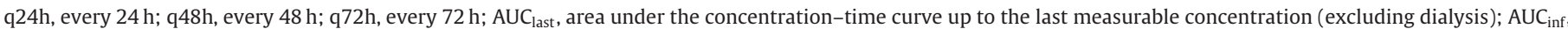

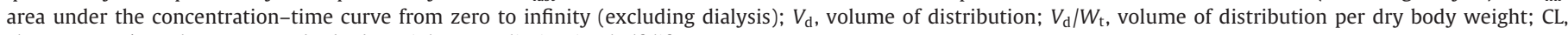
clearance; $\mathrm{CL} / W_{\mathrm{t}}$, clearance per dry body weight; $t_{1 / 2}$, elimination half-life.

${ }^{a}$ Values are given as the mean (standard deviation).

total concentration for patients having received $1 \mathrm{~g}$ or $2 \mathrm{~g}$, but was only 2 -fold lower for those having received $3 \mathrm{~g}$. The median $V_{\mathrm{d}}$ across dosing regimens for free concentrations was $0.5 \mathrm{~L} / \mathrm{kg}$, which is approximately two times higher than the corresponding $V_{\mathrm{d}}$ for the total concentrations. Median free temocillin clearance was $0.4 \mathrm{~mL} / \mathrm{min} / \mathrm{kg}$, which is approximately four times higher than the total temocillin clearance. Note that free clearance was highest in patients having received a $1 \mathrm{~g}$ dose and appears to reduce with increasing dosage. The elimination half-life (median, 24-26 h) was prolonged in ESRD patients and was similar across free and total temocillin concentrations.

\subsection{Haemodialysis efficacy}

Summaries of the haemodialysis efficacy for temocillin are shown in Table 3. Residual median temocillin concentrations before starting dialysis were $13.4 \mathrm{mg} / \mathrm{L}$ and $40 \mathrm{mg} / \mathrm{L}$ for free and total concentrations, respectively. They were markedly reduced during haemodialysis across the three dosing regimens so as to reach median concentrations of $6.5 \mathrm{mg} / \mathrm{L}$ (free) and $16 \mathrm{mg} / \mathrm{L}$ (total). Median haemodialysis clearance for free temocillin was $113 \mathrm{~mL} / \mathrm{min}$, which is approximately double the value found for the total concentration. The interdialytic $(4 \mathrm{~h})$ and intradialytic $(>20 \mathrm{~h})$ elimination half-lives were significantly different $(P \leq 0.025)$. The estimated fraction eliminated by dialysis for the free concentration varied from $48 \%$ to $59 \%$. The URR was ca. $70 \%$ across all dosing groups.

\subsection{Pharmacodynamics}

The causative infectious pathogen was identified in 11 patients (69\%) and it belonged to the Enterobacteriaceae family. A recent
Table 3

Temocillin dialysis efficiency.

\begin{tabular}{llll}
\hline Parameter & $1 \mathrm{~g} \mathrm{q} 24 \mathrm{~h}$ & $2 \mathrm{~g} \mathrm{q} 48 \mathrm{~h}$ & $3 \mathrm{~g} \mathrm{q} 72 \mathrm{~h}$ \\
\hline $\begin{array}{l}\text { URR }(\%) \\
\text { Total concentrations }\end{array}$ & $63.3(12.1)$ & $72.4(7.9)$ & $71.1(9.2)$ \\
$\mathrm{CL}_{\mathrm{HD}}(\mathrm{mL} / \mathrm{min})$ & $67(22)$ & $39(18)$ & $77(26)$ \\
$t_{1 / 2 \mathrm{HD}}(\mathrm{h})$ & $3.0(0.5)$ & $4.3(1.5)$ & $3.0(1.1)$ \\
$\mathrm{Fe}(\%)$ & $58.9(7.2)$ & $48.6(9.2)$ & $58.5(11.0)$ \\
$C_{\mathrm{s}, \mathrm{pre}}(\mathrm{mg} / \mathrm{L})$ & $29(11.7)$ & $45(20)$ & $40(19)$ \\
$C_{\mathrm{s}, \text { post }}(\mathrm{mg} / \mathrm{L})$ & $12(4.4)$ & $23(10)$ & $16(8)$ \\
Free concentrations & & & \\
$\mathrm{CL}_{\mathrm{HD}}(\mathrm{mL} / \mathrm{min})$ & $106(9)$ & $136(83)$ & $113(61)$ \\
$t_{1 / 2 \mathrm{HD}}(\mathrm{h})$ & $4.1(0.3)$ & $3.6(2.1)$ & $3.2(1.2)$ \\
$\mathrm{Fe}(\%)$ & $48.3(4)$ & $59(15)$ & $58(12)$ \\
$C_{\mathrm{s}, \mathrm{pre}}(\mathrm{mg} / \mathrm{L})$ & $3.4(7.4)$ & $13(8.7)$ & $15.1(6.6)$ \\
$C_{\mathrm{s}, \mathrm{post}}(\mathrm{mg} / \mathrm{L})$ & $7.1(4.4)$ & $4.7(2.9)$ & $6.5(3.5)$
\end{tabular}

q24h, every $24 \mathrm{~h}$; q48h, every $48 \mathrm{~h}$; q72h, every $72 \mathrm{~h}$; URR, urea reduction ratio; $\mathrm{CL}_{\mathrm{HD}}$, dialysis clearance; $t_{1 / 2} \mathrm{HD}$, elimination half-life during haemodialysis; Fe, fraction eliminated by dialysis; $C_{\mathrm{s} \text {,pre }}$ and $C_{\mathrm{s} \text {,post }}$, serum concentrations of temocillin at the beginning and end of haemodialysis, respectively.

a Values are given as the mean (standard deviation).

Belgian survey reported $\mathrm{MIC}_{50 / 90}$ values of $8 / 16 \mathrm{mg} / \mathrm{L}$ for temocillin against these organisms [22]. Table 4 summarises the proportion of the dosing interval during which the free temocillin concentration remains above an MIC of $8 \mathrm{mg} / \mathrm{L}\left(f \mathrm{~T}_{>}\right.$MIC8 $)$or $16 \mathrm{mg} / \mathrm{L}\left(f \mathrm{~T}_{>\mathrm{MIC16}}\right)$ taken as tentative susceptibility breakpoint values for temocillin $[21,24]$. These values ranged from $78 \%$ to $90 \%$ and from $48 \%$ to $71 \%$ when considering $f \mathrm{~T}_{>\mathrm{MIC} 8}$ and $f \mathrm{~T}_{>\mathrm{MIC16}}$, respectively.

\section{Discussion}

This study is the first to substantiate with robust PK data that temocillin is a reliable option to treat serious Gram-negative 
Table 4

Percentages of the dosing interval that serum levels of temocillin are above clinically relevant minimum inhibitory concentrations of pathogens. ${ }^{\text {a }}$

\begin{tabular}{|c|c|c|c|}
\hline PK/PD criterion ${ }^{\mathrm{b}}$ & $1 \mathrm{~g} \mathrm{q} 24 \mathrm{~h}$ & $2 \mathrm{~g} \mathrm{q} 48 \mathrm{~h}$ & $3 \mathrm{~g} \mathrm{q} 72 \mathrm{~h}$ \\
\hline$\% f \mathrm{~T}>8 \mathrm{mg} / \mathrm{L}$ & $78(33)$ & $88(18)$ & $89.5(20)$ \\
\hline$\% f \mathrm{~T}>16 \mathrm{mg} / \mathrm{L}$ & $48(37)$ & $67(30)$ & $71(24)$ \\
\hline
\end{tabular}

$\mathrm{PK} / \mathrm{PD}$, pharmacokinetic/pharmacodynamic; q24h, every $24 \mathrm{~h}$; q48h, every $48 \mathrm{~h}$; q72h, every $72 \mathrm{~h}$.

a Values are given as the mean (standard deviation).

b Percentage of the dosing interval that free serum temocillin concentrations are $>8 \mathrm{mg} / \mathrm{L}$ and $>16 \mathrm{mg} / \mathrm{L}$, respectively.

infections in ESRD patients when administered thrice weekly on dialysis days only. Previous research on temocillin during haemodialysis was limited to two studies conducted in the $1980 \mathrm{~s}$ with a small number $(n=5-7)$ of patients and using older and less efficient low-flux dialysers. The performance of these dialysers in eliminating temocillin is inferior to that of contemporary highflux dialysers, and modern pharmacokinetic/pharmacodynamic (PK/PD) insights about parameters predicting the activity of $\beta$ lactams were not yet fully developed $[11,25]$. The applicability of these outdated data to current practice is therefore questionable.

The pattern of Gram-negative organisms observed in this study is similar to that typically seen in haemodialysis patients, with E. coli and Klebsiella spp. being the most frequent organisms isolated [4]. The incidence of Gram-negative bacteraemia in dialysis patients has increased during recent years and it is associated with an unfavourable prognosis with a 3-month mortality of $28.6 \%$ as well as non-dialysis access-related infection such as diabetic foot ulcer or urinary and intra-abdominal infection [5]. There is a worrisome increase in antibiotic resistance in Gram-negative organisms with resistance percentages of $>30 \%$ for fluoroquinolones, trimethoprim/sulfamethoxazole and conventional $\beta$-lactams such amoxicillin/clavulanic acid, forcing clinicians to resort to broad-spectrum drugs such as carbapenems [3]. Temocillin is a strategically important alternative to carbapenems in this context [12].

We observed a consistently high systemic exposure to temocillin. The total volume of distribution is in agreement with literature data [25] and does not appear to be significantly affected by renal insufficiency, as previously reported $[11,14]$. Free AUC reaches $35-50 \%$ of total AUC depending on the dose, which is in the same range as recent observations in severely ill patients hospitalised in intensive care units [24]. Both types of patients frequently experience lower drug protein binding than healthy volunteers $[23,26]$, for whom temocillin free concentrations account for only $15 \%$ of total temocillin serum concentrations [10].

We demonstrate that temocillin pharmacokinetics are markedly different during haemodialysis compared with the interdialytic interval, with a clearance of $113 \mathrm{~mL} / \mathrm{min}$ vs. $26 \mathrm{~mL} / \mathrm{min}$ and a serum half-life of $3.6 \mathrm{~h}$ vs. $24 \mathrm{~h}$, respectively. This emphasises the need to administer the drug after the dialysis session to accommodate for intradialytic losses.

Temocillin has an extensive dialysability due to its low molecular weight $(<500 \mathrm{Da})$ and its high degree of water solubility, which is further enhanced by the low serum albumin levels frequently observed in sick dialysis patients, as illustrated in this study [23]. During the interdialytic period, temocillin exhibits complex, non-linear pharmacokinetics, which can partly be attributed to saturable protein binding [27]. Binding sites for temocillin have not been identified, but it has been suggested that proteins other than albumin could be involved especially at high temocillin concentrations [28]. This could be of importance, particularly in inflammatory situations where the serum concentration of albumin tends to decrease while those of other proteins such as $\alpha$-1-acid glycoprotein tend to increase. Non-linear pharmacokinetics may also be partly explained by an increasing extrarenal elimination with decreasing glomerular filtration (likely biliary secretion), which may become the main elimination pathway in patients with ESRD [14]. Interestingly, the current data suggest a decrease in clearance of free drug with increasing dose (only borderline statistically significant, probably due to the limited sample size), which is the hallmark of a mixed-order elimination process. This explains the subtherapeutic drug exposure observed with the lowest dose of $1 \mathrm{~g}$ per 24 -h interval. It could correspond to a saturation of biliary secretion at high antibiotic concentrations because this process requires the intervention of active transporters [27].

Regarding temocillin pharmacodynamics, its overall efficacy is best predicted, as for all $\beta$-lactam antibiotics, by the time during which the free concentration remains above the MIC of the offending bacteria $\left(f T_{>M I C}\right)[13]$. There is, however, no clear consensus on the fraction of the dosing interval during which the free concentration has to remain above this MIC value. Animal models suggest that a $\mathrm{T}_{>\text {MIC }}$ of $29-34 \%$ is required to achieve bacteriostasis against most susceptible organisms when using discontinuous administration [13].

Mathematical models based on Monte Carlo simulations using a cut-off $f \mathrm{~T}_{>\text {MIC }}$ of $40 \%$ suggest for temocillin a clinical PK/PD breakpoint of $8-16 \mathrm{mg} / \mathrm{L}$ [24], a value of the same order of magnitude as the $\mathrm{MIC}_{90}$ for most Enterobacteriaceae [22]. This target was reached for the $2 \mathrm{~g}$ q48 $\mathrm{h}$ and $3 \mathrm{~g}$ q72h dosing regimens and only partially reached for the $1 \mathrm{~g}$ q24h regimen when considering an MIC of $16 \mathrm{mg} / \mathrm{L}$. In order to maximise bacterial killing and thus therapeutic efficacy, values of $f \mathrm{~T}_{>\text {MIC }}$ as high as $50-100 \%$ have also been proposed when dealing with more complicated infections in immunocompromised patients [22,29]. This goal could not be achieved for patients receiving $1 \mathrm{~g}$ q24h for whom temocillin $f \mathrm{~T}_{>\mathrm{MIC} 16}$ was $<50 \%$. Conversely, this value was obtained for the majority of patients receiving $2 \mathrm{~g}$ q48h or $3 \mathrm{~g}$ q72h, with free concentrations remaining above an MIC of $8 \mathrm{mg} / \mathrm{L}$ or $16 \mathrm{mg} / \mathrm{L}$ during ca. $90 \%$ and $70 \%$ of the dosing interval, respectively. However, still higher exposure may be needed in order to prevent the emergence of more resistant mutants, with trough values for free concentrations as high as four times the MIC being recommended to avoid selection of resistant subpopulations [30]. Based on these considerations, it is obvious that the doses of temocillin recommended in the Summary of Product Characteristics, being $0.5 \mathrm{~g}$ q24h and $1 \mathrm{~g} \mathrm{q} 48 \mathrm{~h}$, will lead to subtherapeutic drug exposure in the majority of patients [10], which may call for revision of these recommendations. Noteworthy, temocillin was well tolerated in this ESRD population.

This study has several limitations. First, we did not evaluate whether rebound occurred in temocillin concentrations after haemodialysis. If so, the half-life might be overestimated. Second, the patients were not all at steady state, thus the potential for drug accumulation with multiple dosing exists. However, haemodialysis was highly efficient at removing temocillin. Therefore, any drug accumulation can be considered insignificant compared with other sources of variability, and we estimated it to be less than one-half of the accuracy of the analytical method (15\%) used. Lastly, and in a more global context, further studies are needed to more definitely establish the optimal PK/PD target for $\beta$-lactams in general, and for temocillin in particular, in order to better define adequate dosing regimens.

\section{Conclusion}

This study demonstrates that temocillin is a safe, effective, strategically interesting, and easy-to-use therapeutic option in ESRD patients undergoing intermittent haemodialysis provided close attention is given to its proper dosing. The approach followed 
in this study could also be used to assess the reliability of other $\beta$ lactams for the treatment of ESRD patients undergoing intermittent haemodialysis. For the three dosing schedules studied, temocillin trough levels before dialysis were relatively independent of the dosing schedule, leaving room to explore the use of higher doses in order to achieve a higher percentage of $f \mathrm{~T}_{>\mathrm{MIC16}}$, and decreasing the risk of the emergence of bacterial resistance while patients are undergoing treatment. In addition, the proposed regimen allows for treatment of both inpatients and outpatients.

\section{Acknowledgments}

The authors are grateful to patients and the on-site nursing/medical team for their participation. The authors especially thank Mirjan Demesmaecker for collecting all samples. FVB is a Senior Research Associate of the Fonds de la Recherche Scientifique (F.R.S.-FNRS).

Funding: This work was supported in part by the Région Wallonne [project TEMOEX-PAND 1217668].

Competing interests: PMT is an unpaid advisor to Eumedica, the registration holder of temocillin. All other authors declare no competing interests.

Ethical approval: The Ethical Committee of AZ Sint-Jan Brugge (Brugge, Belgium), the hospital where the patients were taken care of, approved the protocol [unique Belgian no. B049201215528]. All patients gave written informed consent. The trial has been registered at http://clinicaltrials.gov under the identifier NCT02285075.

\section{References}

[1] Vandecasteele SJ, Kurella Tamura M. A patient-centered vision of care for ESRD: dialysis as a bridging treatment or as a final destination? J Am Soc Nephrol 2014:25:1647-51.

[2] van Dijk PC, Jager KJ, de Charro F, Collart F, Cornet R, Dekker FW, et al. Renal replacement therapy in Europe: the results of a collaborative effort by the ERAEDTA registry and six national or regional registries. Nephrol Dial Transplant 2001;16:1120-9.

[3] Pop-Vicas A, Strom J, Stanley K, D’Agata EMC. Multidrug-resistant Gramnegative bacteria among patients who require chronic hemodialysis. Clin J Am Soc Nephrol 2008;3:752-8.

[4] Murray EC, Marek A, Thomson PC, Coia JE. Gram-negative bacteraemia in haemodialysis. Nephrol Dial Transplant 2015;30:1202-8.

[5] Girndt M. Bacteraemia in haemodialysis patients-not always Staphylococcus aureus. Nephrol Dial Transpl 2015;30:1055-7.

[6] Ahern JW, Possidente CJ, Hood V, Alston WK. Cefazolin dosing protocol for patients receiving long-term hemodialysis. Am J Health Syst Pharm 2003;60:178-81.

[7] Vandecasteele SJ, De Vriese AS. Vancomycin dosing in patients on intermittent hemodialysis. Semin Dial 2011;24:50-5.

[8] Loo AS, Neely M, Anderson EJ, Ghossein C, McLaughlin MM, Scheetz MH. Pharmacodynamic target attainment for various ceftazidime dosing schemes in high-flux hemodialysis. Antimicrob Agents Chemother 2013;57:5854-9.

[9] Mingeot-Leclercq MP, Tulkens PM. Aminoglycosides: nephrotoxicity. Antimicrob Agents Chemother 1999;43:1003-12.
[10] Temocillin summary of product characteristics. http://www.medicines.org.uk [last updated 2012].

[11] Boelaert J, Daneels R, Schurgers M, Mellows G, Swaisland AJ, Lambert AM, et al Effect of renal function and dialysis on temocillin pharmacokinetics. Drugs 1985;29(Suppl. 5):109-13.

[12] Livermore DM, Tulkens PM. Temocillin revived. J Antimicrob Chemother 2009;63:243-5.

[13] Craig WA. Basic pharmacodynamics of antibacterials with clinical applications to the use of $\beta$-lactams, glycopeptides, and linezolid. Infect Dis Clin North Am 2003;17:479-501.

[14] Boelaert J, Daneels R, Schurgers M, Lambert AM, Van Landuyt HW, Mellows G, et al. The pharmacokinetics of temocillin in patients with normal and impaired renal function. J Antimicrob Chemother 1983;11:349-56.

[15] Stryjewski ME, Szczech LA, Benjamin Jr DK, Inrig JK, Kanafani ZA, Engemann JJ, et al. Use of vancomycin or first-generation cephalosporins for the treatment of hemodialysis-dependent patients with methicillin-susceptible Staphylococcus aureus bacteremia. Clin Infect Dis 2007;44:190-6.

[16] Miranda Bastos AC, Vandecasteele SJ, Tulkens PM, Spinewine A, Van Bambeke F. Development and validation of a high performance liquid chromatography assay for the determination of temocillin in serum of haemodialysis patients. J Pharm Biomed Anal 2014;90:192-7.

[17] Ngougni Pokem P, Miranda Bastos AC, Tulkens PM, Wallemacq P, Van Bambeke F, Capron A. Validation of a HPLC-MS/MS assay for the determination of total and unbound concentration of temocillin in human serum. Clin Biochem 2015;48:542-5.

[18] Bauer LA. Drug dosing in special populations: renal and hepatic disease, dialysis, heart failure, obesity, and drug interactions. In: Weitz M, Pancotti R, editors. Applied clinical pharmacokinetics. McGraw-Hill Medical; 2008. p. 73-7.

[19] Manley HJ, Bailie GR, McClaran ML, Bender WL. Gentamicin pharmacokinetics during slow daily home hemodialysis. Kidney Int 2003;63:1072-8.

[20] Winter ME. Dialysis of drugs. In: Troy DB, editor. Basic clinical pharmacokinetics. Baltimore, MD: Lippincott Williams \& Wilkins; 2004. p. 111-27.

[21] Andrews JM, Jevons G, Walker R, Ashby J, Fraise AP. Temocillin susceptibility by BSAC methodology. J Antimicrob Chemother 2007;60:185-7.

[22] Rodriguez-Villalobos H, Bogaerts P, Berhin C, Bauraing C, Deplano A, Montesinos I, et al. Trends in production of extended-spectrum $\beta$-lactamases among Enterobacteriaceae of clinical interest: results of a nationwide survey in Belgian hospitals. J Antimicrob Chemother 2011;66:37-47.

[23] Benet LZ, Massoud N, Gambertoglio JG. The pharmacokinetic basis for drug treatment. New York, NY: Raven Press; 1984.

[24] Laterre PF, Wittebole X, Van de Velde S, Muller AE, Mouton JW, Carryn S, et al. Temocillin (6g daily) in critically ill patients: continuous infusion versus three times daily administration. J Antimicrob Chemother 2015;70:891-8.

[25] Leroy A, Humbert G, Fillastre JP, Borsa F, Godin M. Pharmacokinetics of temocillin (BRL 17421) in subjects with normal and impaired renal function. J Antimicrob Chemother 1983;12:47-58.

[26] Roberts JA, Lipman J. Pharmacokinetic issues for antibiotics in the critically ill patient. Crit Care Med 2009;37:840-51.

[27] Hoffler D, Koeppe P. Temocillin pharmacokinetics in normal and impaired renal function. Drugs 1985;29(Suppl. 5):135-9.

[28] Carryn S, Mouton JW, Couwenbergh N, Tulkens PM. Temocillin protein binding is concentration-dependent and not restricted to albumin. In: 18th European Congress of Clinical Microbiology and Infectious Diseases (ECCMID). 2008 [0146].

[29] Roberts JA, Paul SK, Akova M, Bassetti M, De Waele JJ, Dimopoulos G, et al DALI: defining antibiotic levels in intensive care unit patients: are current (-lactam antibiotic doses sufficient for critically ill patients? Clin Infect Dis 2014;58:1072-83.

[30] Tam VH, Schilling AN, Neshat S, Poole K, Melnick DA, Coyle EA. Optimization of meropenem minimum concentration/MIC ratio to suppress in vitro resistance of Pseudomonas aeruginosa. Antimicrob Agents Chemother 2005;49: 4920-7. 